\title{
AN EXPERIMENTAL STUDY OF THE EFFECT OF THE EXTERNAL LOAD ON THE STIFFNESS AND LONGEVITY OF SPINDLE BEARINGS
}

\author{
HUNG PHAM VAN ${ }^{1}$, DUONG NGUYEN THUY ${ }^{2 *}$, TAM PHAM MINH ${ }^{3}$ \\ ${ }^{1,2}$ Lecturer, School of Mechanical Engineering, Hanoi University of Science and Technology, Viet Nam \\ ${ }^{3}$ Faculty of Vehicle and Energy Engineering, Vinh University of Technology Education, Viet Nam
}

\begin{abstract}
The stiffness of the spindle bearings of CNC machines is an important criterion to evaluate the quality of machining process. The initial stiffness of the spindle bearings is caused by pre-load. During machining process, the spindle bearings are worn due to external loads, including cutting force and rotational speed. The bearing wear reduces the stiffness of the spindle bearings and decreases machining accuracy. Mentions related study in the literatures: This study presents various stiffness of the spindle bearings under external loads in laboratory condition. Based on the relationship between the stiffness and longitudinal wear of the spindle, bearings respect to the working time, and the stiffness limit is used to predict the remaining time, reliability and period for adjusting the pre-load to maintain stability and machining accuracy.

KEYWORDS: Spindle Bearings, CNC Machine, Spindle Bearing Stiffness, Wear of Bearing, Longevity \& Reliability
\end{abstract}

Received: Mar 08, 2020; Accepted: Mar 28, 2020; Published: Apr 29, 2020; Paper Id.: IJMPERDJUN202017

\section{INTRODUCTION}

The CNC machine tool has a high stiffness of spindle bearings, therefore the machining accuracy is high and stable. Moreover, the $\mathrm{CNC}$ machine is normally used for a single unit and small series production that has fluctuating external load impacting on the main bearing. Note that the spindle bearings are subjected to an external load including cutting force and rotation speed. In addition, the spindle bearings require accuracy of $1 \mu \mathrm{m}$ (grinding, boring) to $100 \mu \mathrm{m}$ (turning, milling) [1], thus initial stiffness is required. However, predicting the rule of stiffness that decreases over time is significantly important. The adjustment period pre-load of bearing maintain the stiffness of the spindle bearings according to working time in general. However, determining adjustment may not be suitable when the external load is unstable.

The stiffness of spindle bearings depends on both the pre-load and the choice of different structures of the main load-bearing assembly. In order to maintain and improve machining accuracy with regard to the stiffness of spindle bearings, the optimal structure for the spindle bearings is selected to ensure the required stiffness [2].

On the other hand, an in-depth study on changing bearings preload, the distance among bearings, number of bearings to increase the stiffness of spindle bearings was done in the research of Tri Prakosa et al [3]. Moreover, Holroyd et al has studied and selected the combination of bearings to determine the relationship between stiffness and vibration of spindle bearings [4]. Rastegari. A et al has determined the reason of the stiffness reduction is due to the wear of the main spindles bearing under external load conditions, including 4 zones [5]. The reduction follows the general rule of wear $[6,7]$ as shown in figure 1 . 


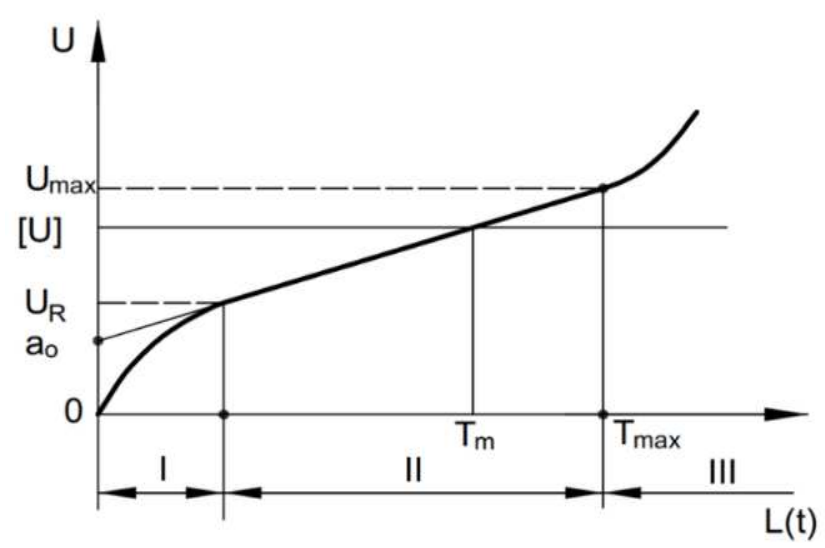

Figure 1: Relationship of Amount of Wear U by Time t Regarding to Friction Distance L.

Figure 1 shows that the running-in stage (I), the wear rate decreases gradually to a stable value. Next, stable wear stage (II), the wear rate has a constant value. In the state, life expectancy mainly lies in this period. Then, severe wear-out stage (III) can be divided into two periods:

Vicinity after $T_{\max }$ : The transition interval is very short, and local damage phenomena begins to happen. For the spindle bearings, vibration begin to have mutations, such as rollers, inner shifts, outer shifts or spacing which occur local failures. Thus, the speed of wear begins to increase.

Severe wear-out, $\mathrm{T}>\mathrm{T}_{\max }$ : The speed of wear first increases significantly, then should be stopped and replaced to prevent the structure of machine and the spindle bearings.

Thus, determining the adjustment points can maintain the pre-load during the stable wear stage of the spindle bearings before the stage III, and the long-term machining accuracy. When moving to stage III, the spindle bearings cannot restore their original stiffness, as the result the friction surface starts to be damaged.

This paper first presents the results of the study on the relationship between stiffness and longitudinal wear of spindle bearings machine $\mathrm{CNC}$ over time. The results is aimed to confirm the hypothesis in Figure 2. Then, the works of determination of the required parameters for calculating life expectancy and reliability based on stiffness when external load changes under laboratory conditions is implemented. The results of paper also can be applied to determine the life expectancy regarding to the stiffness when lubrication appears.

\section{THE METHOD OF CALCULATING LONGEVITY REGARDING TO THE STIFFNESS OF THE SPINDLE BEARINGS}

From the general wear-rule in figure 1, it assumes that the changing stiffness rule $\mathrm{J}$ according to time or distance of friction as shown in figure 2, under normal wear conditions, also includes three stages: in the first stage, running in, stiffness rate is gradually decreases; in the stable stage, the rate of stiffness reduction is constant ; and in the stage of rapidly reducing stiffness, the rate of stiffness reduction increase extremely. 


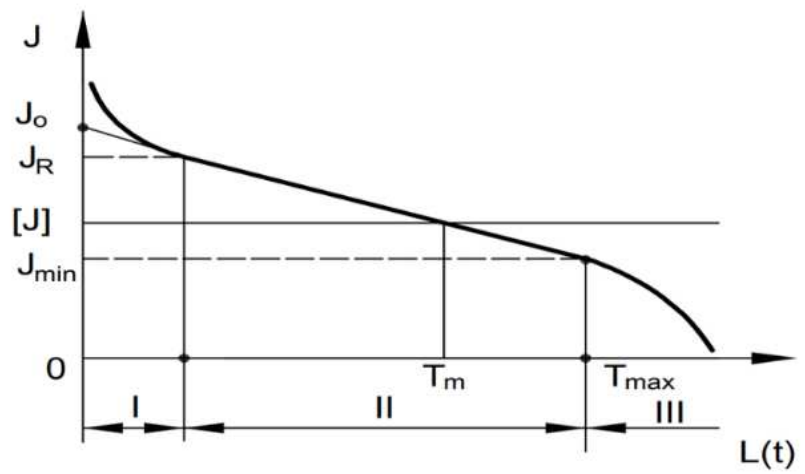

Figure 2: Relationship Between Stiffness J and Time T or Friction Distance L.

From the relationship between wear and longevity, reliability [7] given the relationship between stiffness $\mathbf{J}$ and longevity, reliability, as shown in figure 3.

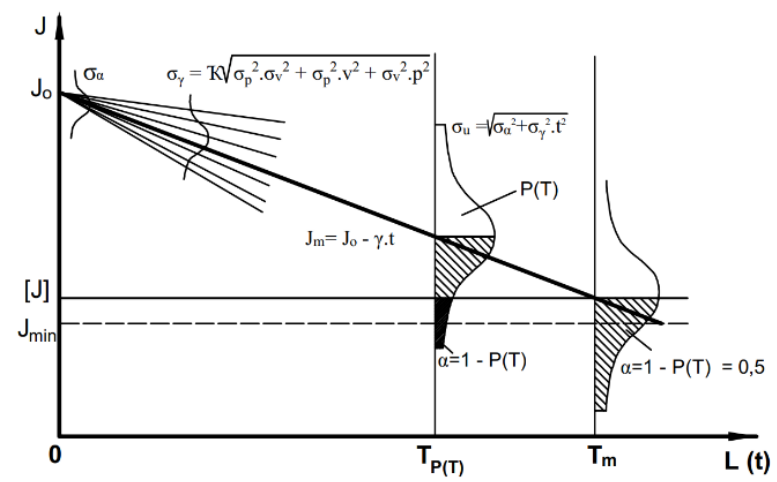

Figure 3: Dependency on Stiffness J Changing Over Time and Reliability

The stiffness of the spindle bearings $J$ changes over time ( $t$ ) which is obeyed to linear rule and is shown by the following equation:

$J_{m}=J_{o}-\gamma_{m} \cdot t$

In which:

$J_{m^{-}}$Average stiffness of the spindle bearings changing over time

$J_{o}$ - Initial stiffness of the spindle bearings

$\gamma_{m}-$ The rate of average stiffness reduction

The average rate of stiffness reduction by time can be calculated using the equation similar to the rate of wear [7]:

$\gamma_{m}=k_{J} \cdot P_{m} \cdot V_{m} \rightarrow \gamma_{m}=k \cdot P_{m} \cdot n_{m}$

In which:

$P_{m}$ - Average load,

$V_{m}-$ Average speed

$n_{m}$ - Average rotation speed,

$\mathrm{k}_{\mathrm{j}}$ and $\mathrm{k}$ are coefficients that can be determined from the experimental results. 
Under normal working conditions, the load and speed can be considered as two random variables with standard deviations of $\sigma_{\mathrm{p}}(\mathrm{N})$ and $\sigma_{\mathrm{n}}(\mathrm{vg} / \mathrm{min})$. Thus, the rate of stiffness reduction $\gamma$ is also a random variable following the law of large numbers, expected standard distributions and standard deviations $\sigma \gamma$ with the density function $\mathrm{f}(\gamma)$ calculated by the formula [7]:

$$
f(\gamma)=\frac{1}{\sigma_{\gamma} \sqrt{2 \pi}} \exp \left\{-\frac{\left[\gamma-\gamma_{j}\right]^{2}}{2 \sigma_{\gamma}{ }^{2}}\right\}
$$

In which:

$$
\begin{aligned}
& \sigma_{\gamma}=\sqrt{D(k p n)}=k \sqrt{\sigma_{p}^{2} \sigma_{n}^{2}+\sigma_{p}^{2} n_{m}^{2}+\sigma_{n}^{2} p_{m}^{2}} \\
& \gamma_{m}=\frac{J_{m}}{T} \\
& \mathrm{~T} \text { - Expected longevity } \\
& \text { D- Variance }
\end{aligned}
$$

The standard deviation of $\mathbf{J}_{\mathrm{m}}$ is calculated:

$$
\sigma_{J}=\sqrt{\sigma_{J o}^{2}+\sigma_{\gamma}^{2} T^{2}}
$$

$P(t)$ is the probability of a non-failover of spindle bearings based on stiffness $J$, corresponding to the working period $t=T$. The probability of non-failing operation of spindle bearings is based on stiffness $J$, which is equal to the area under the probability density curve of $\mathrm{J}$ : $\mathrm{f}(\mathrm{J})$ and is in the range $[\mathrm{J}] \leq \mathrm{J} \leq \mathrm{J}_{0}$ (Figure 3 ). The working probability $\mathrm{P}(\mathrm{t}$ ) typical for continuous work ability is calculated by the Laplace operator [7] as follows:

$$
P(\mathrm{t})=0,5+\phi\left[\frac{J_{0}-\gamma_{m} T-[J]}{\sqrt{\sigma_{J o}^{2}+\sigma_{\gamma}^{2} T^{2}}}\right]
$$

In which:

$\Phi$ - Laplace operator;

$T$ - Expected longevity;

$\sigma_{J o}-$ Standard deviation of initial stiffness;

$\sigma_{\gamma}$ - Standard deviation rate of stiffness reduction;

$[J]$ - Remaining stiffness allowed.

The different arguments of the Laplace function $(\mathrm{U} \alpha)$ depend on the reliability. The life expectancy equation regarding to stiffness and the reliability will be

$$
U_{\alpha}\left(\sqrt{\sigma_{J o}^{2}+\sigma_{\gamma}^{2} T^{2}}\right)=\mathrm{J}_{0}-\gamma_{J} T-[J]
$$

Equation (8) has two solutions T1 and T2. However, 50\% confidence is minimal, the solution of this equation must be within $0<\mathrm{T}<\mathrm{T}_{\mathrm{m}}$. The average life expectancy $\mathrm{T}_{\mathrm{m}}$ of the spindle bearings that have the remaining stiffness $[\mathrm{J}]$ 
allowed will be determined by the formula:

$T_{m}=\frac{J_{0}-[J]}{\gamma_{m}}$

\section{EXPERIMENTAL EQUIPMENT SYSTEM}

Based on the principle of stiffness measurement and total wear measurement to determine the life of lathe spindle according to (ISO 13041 - $1: 2004$ ), (name of authors) developed the diagram of the experimental equipment system [8], as shown in figure 4. The system is located on the CNC eclipse 300 spindle bearings. In this system, 02 pneumatic cylinders are used in the vertical axis and the direction of diameter is adjusted pressure corresponding to the computed cutting force. In order to reduce time, the experiment was conducted in the absence of lubricant. The main bearing assembly is guaranteed to work in stable condition, the working temperature is maintained below $60^{\circ} \mathrm{C}$ by the pneumatic cooling system $[9,10]$. The temperature sensors are attached to the pressure flow adjustment $\mathrm{v}$ to the outer case of bearings to control the proper cooling airflow. The axial displacement and vertical wear amount are measured by using the Mitutoyo 1/1000 meter, with measuring range : $0-0.14 \mathrm{~mm}$; Split : $0.001 \mathrm{~mm}$.

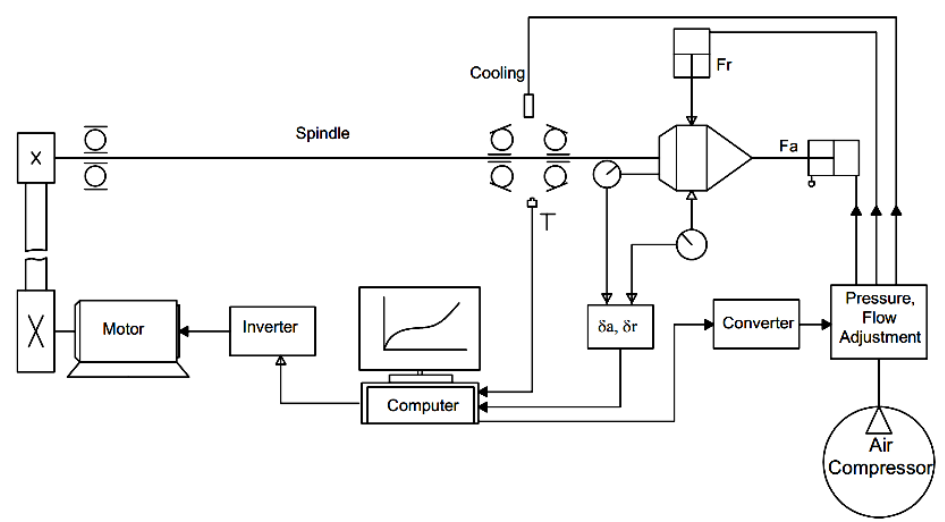

Figure 4: Schematic View of the Experimental Equipment.

In the experimental equipment system, the CNC eclipse 300 machine has a pair of NSK 7210 roller bearings mounted in the back-to-back style and average load. The value of the $250 \mathrm{~N}$ preload in the vertical direction corresponding to the axial displacement of the roller is $\delta_{\mathrm{a}}=6 \mu \mathrm{m}$ [11]. It is assumed that the value of $\left[\delta_{\mathrm{a}}\right] \sim 5 \mu \mathrm{m}$ is also the maximum total amount of wear in the vertical axis allowed by the bearing assembly [8]. The diagram of the experimental equipment system is shown in figure 5 . 


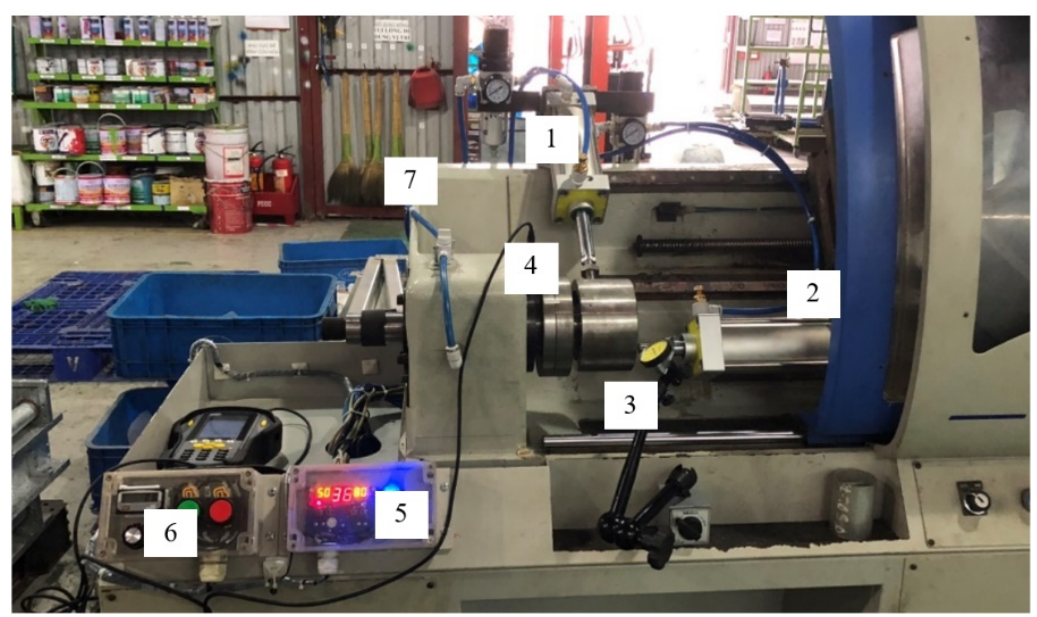

Figure 5: Experimental Equipment Assessing the Quality of Main Bearing Assemblies

on Eclipse 300 CNC Lathes. 1. Cylinders Producing Radial Force; 2. Cylinder Producing Axial Force ; 3.

Indicator ; 4. Main Bearing Assembly of CNC Lathes; 5. Temperature Monitoring and Control Unit; 6. Main Bearing Speed Controller; 7. Pneumatic Cooling Lines.

The basic parameters of the experiments are shown in table 1. Experiments conducted according to the tests with external loads are presented in table 2.

Table 1: The Basic Parameter of the Experiments

\begin{tabular}{|c|l|l|}
\hline No & \multicolumn{1}{|c|}{ Specification } & \multicolumn{1}{c|}{ Value $/$ Parameters } \\
\hline 1 & $7210 \mathrm{~B}$ of NSK & $\mathrm{D}=90 \mathrm{~mm}, \mathrm{~d}=50 \mathrm{~mm}, \mathrm{C}_{\mathrm{r}}=60500 \mathrm{~mm}, \alpha=15$ \\
\hline 2 & Rotation speed, $\mathrm{n}$ & $1800,2000,2200 \mathrm{vg} / \mathrm{ph}$ \\
\hline 3 & Equivalent load, $\mathrm{Pt}$ & $1310,1915,2520 \mathrm{~N}$ \\
\hline 4 & Lubrication & Not lubricated \\
\hline 5 & Preriod of time & $6 \mathrm{~h}$ \\
\hline 6 & Cooling & Compressed air requirement $\mathrm{T}<60^{\circ} \mathrm{C}$ \\
\hline
\end{tabular}

Table 2: External Load Parameter of Experiments

\begin{tabular}{|l|c|c|c|c|c|}
\hline Specification & TN1 & TN2 & TN3 & TN4 & TN5 \\
\hline $\mathrm{P}_{\mathrm{t}}(\mathrm{N})$ & 1310 & 2520 & 1310 & 2520 & 1915 \\
\hline $\mathrm{n}(\mathrm{vg} / \mathrm{ph})$ & 1800 & 1800 & 2200 & 2200 & 2000 \\
\hline
\end{tabular}

In these experiments with the different external loads $(\mathrm{P}, \mathrm{n})$, these steps were implemented as follows:

First, set the pre-load to create initial tension for bearings according to the manufacturer, the value of the preload is $\mathrm{F}_{\text {Preload }}=250 \mathrm{~N}$. Then, after each period of time $\mathrm{t}=6 \mathrm{~h}$, stop the machine and make a measure of stiffness and total wear along the axis. Note that, each of the experiment must be repeated 3 times to ensure measurement accuracy.

Stiffness measurement $\mathbf{J}(\mathrm{N} / \mu \mathrm{m})$ is determined as shown in following steps: First, determine the test standard measuring in the direction of the glass; Impact of radial force $\mathrm{F}_{\mathrm{r}}$; then, determine the displacement of the glass direction at the measuring position y $(\mu \mathrm{m})$, next, Transposition measurement is made with 20 perimeter measurement points; finally, determine the rigidiy $\mathrm{J}=\mathrm{F}_{\mathrm{r}} / \mathrm{y}(\mathrm{N} / \mu \mathrm{m})[2]$.

Moreover, the total wear measurement $\delta(\mu \mathrm{m})$ is determined as follows: Firstly, determine the measurement standard along the vertical axis; secondly, put impact on axial force; thirdly, determine axial displacement $\delta$ ( $\mu \mathrm{m})$; lastly, 
repeat steps $1,2,3$ and take the average value to eliminate errors.

\section{RESULTS AND DISSCUSSIONS}

\section{Experimental Results}

The results of the experiments determining the stiffness of the spindle bearings in the radial direction and total longitudinal wear with respect to time in the experiments are shown in table 3.

Table 3: Siffness y of the Spindle Bearings in the Radial Direction and Total Longitudinal Wear in Different External Loading Conditions with Respect to Time Periods

\begin{tabular}{|c|c|c|c|c|c|c|c|c|c|c|c|c|c|c|c|c|}
\hline \multirow{3}{*}{$\mathrm{TN}$} & \multicolumn{2}{|c|}{$6(\mathrm{~h})$} & \multicolumn{2}{|c|}{$12(\mathrm{~h})$} & \multicolumn{2}{|c|}{$18(\mathrm{~h})$} & \multicolumn{2}{|c|}{$24(\mathrm{~h})$} & \multicolumn{2}{|c|}{$30(\mathrm{~h})$} & \multicolumn{2}{|c|}{$36(\mathrm{~h})$} & \multicolumn{2}{|c|}{$42(\mathrm{~h})$} & \multicolumn{2}{|c|}{48 (h) } \\
\hline & $\delta$ & $\mathrm{J}$ & $\delta$ & $\mathrm{J}$ & $\delta$ & $\mathrm{J}$ & $\delta$ & $\mathrm{J}$ & $\delta$ & $\mathrm{J}$ & $\delta$ & $\mathrm{J}$ & $\delta$ & $\mathrm{J}$ & $\delta$ & $\mathrm{J}$ \\
\hline & $(\mu \mathrm{m})$ & $(\mathrm{N} / \mu \mathrm{m})$ & $(\mu \mathrm{m})$ & $(\mathrm{N} / \mu \mathrm{m})$ & $(\mu \mathrm{m})$ & $(\mathrm{N} / \mu \mathrm{m})$ & $(\mu \mathrm{m})$ & $(\mathrm{N} / \mu \mathrm{m})$ & $(\mu \mathrm{m})$ & $(\mathrm{N} / \mu \mathrm{m})$ & $(\mu \mathrm{m})$ & $(\mathrm{N} / \mu \mathrm{m})$ & $(\mu \mathrm{m})$ & $(\mathrm{N} / \mu \mathrm{m})$ & $(\mu \mathrm{m})$ & $(\mathrm{N} / \mu \mathrm{m})$ \\
\hline 1 & 1 & 352 & 2 & 315 & 2 & 301 & 3 & 292 & 4 & 246 & 4 & 234 & 5 & 218 & 6 & 192 \\
\hline 2 & 1 & 359 & 2 & 327 & 3 & 310 & 4 & 289 & 4 & 248 & 5 & 225 & 6 & 200 & & \\
\hline 3 & 1 & 362 & 2 & 332 & 3 & 280 & 4 & 265 & 5 & 216 & 6 & 197 & & & & \\
\hline 4 & 1 & 348 & 2 & 314 & 3 & 282 & 4 & 248 & 6 & 199 & & & & & & \\
\hline 5 & 1 & 347 & 2 & 340 & 3 & 308 & 4 & 276 & 4 & 267 & 5 & 212 & 6 & 196 & & \\
\hline
\end{tabular}

Based on the data in table 3, a graph of the variation of stiffness and total longitudinal wear of the spindle bearings over time according to different conditions of external load is shown in figure 6 .

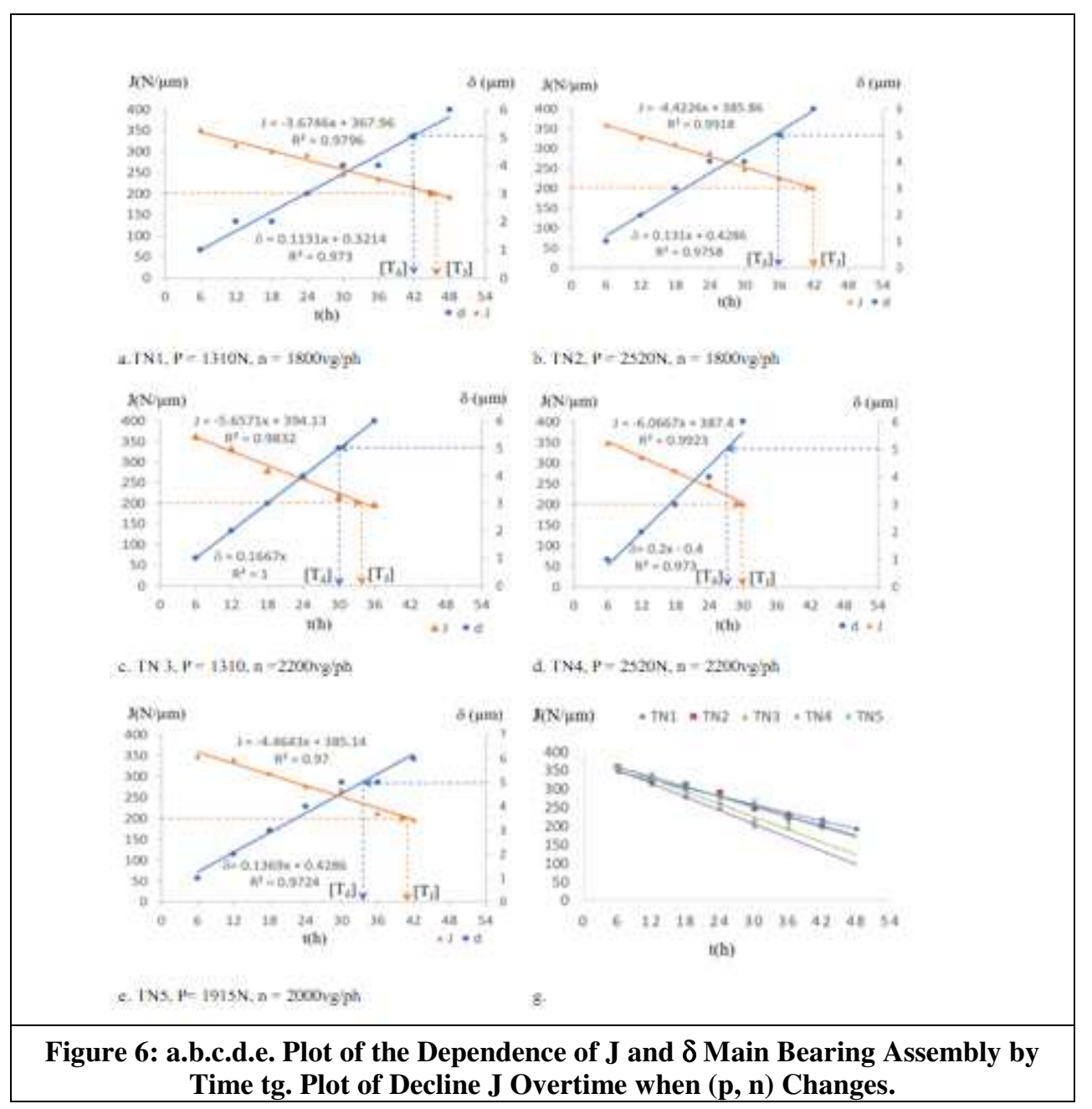


Experimental results show that the stiffness of the spindle bearings has a linear dependence on time during the stable working period under all experimental conditions (figure $6 \mathrm{~g}$ ). Therefore, the graphical representation of the stiffness principal over time in Figure 2 is appropriate to what and is the basis for calculating longevity and reliability for the main bearing assembly.

Stiffness $\mathrm{J}$ and total wear $\delta$ of the spindle bearing overtime at different external load values $(\mathrm{P}$ and $\mathrm{n})$ are inversely related with time (Figure $6 \mathrm{a}, \mathrm{b}, \mathrm{c}, \mathrm{d}$, e). When the total wear increases linearly with working time, the stiffness also decreases linearly. This shows that the main cause of stiffness reduction of the spindle bearings is due to the wear of the spindle bearings.

By loading each specific external load zone (P and $\mathrm{n}$ ) with the allowable value of stiffness [J] of spindle bearings, total wear value $\delta$ is fully determined. This can also be considered as the total allowable wear amount [ $\delta]$ of the spindle bearings.

Research results show that it is likely to determine the initial adjustment time of main bearing assembly according to $[\mathrm{J}]$ or $[\delta]$. The time adjusting the initial tension of the main bearing assembly must be entirely within the rigidity area $\mathrm{J}$ or the amount of wear $\mathrm{U}$ linearly and changes over time to recover the original rigidity.

When the external load changes with a value $[\mathrm{J}]$, the total wear amount $\delta$ has different values. Thus, based on a value $\delta$, choice of adjustment time $t$ is not highly accurate. On the other hand, determining the amount of movement due to wear during working is very difficult and complicated. Because of the measurement standard, it is hard to stablize during a long working time, while determining the stiffness of the spindle bearing in the radial direction is easier.

The experiment results show that the life of the spindle bearing will be $12-15 \%$ longer when based on stiffness [J] compared to the determination of the movement amount allowed [ $\delta]$.

\section{CONCLUSIONS}

- The stiffness and total wear value of the spindle bearings CNC machine tool linearly changes over time during a period of stable and opposite work, and completely determined by the experimental equipment system.

- The time adjusting pre-load of the spindle bearings could be determined through the total wear value $\delta$ but not exactly by adjusting to the stiffness $\mathrm{J}$.

- In laboratory conditions with variable external load values, the life of the spindle bearings has been determined by stiffness, with a probability of 50, 90, 95, 99, and 999\% non-broken working.

- The results of the study are the basis for determining longevity and reliability depending upon the stiffness of the spindle bearings. CNC machine in condition with having lubricant will need to determine rapid factor at the experiment.

\section{ACKNOWLEDGEMENTS}

This research is funded by the Ha Noi University of science and Technology (HUST) under project member T2018 - PC 037 


\section{REFERENCES}

1. Eduado Torres Peres. (2015). Study of vibration severity assessment for Machine Tool spindles within Condition Monitoring, Master Degree Project, Stockholm, Sweden.

2. Momir Šarenac. (1999) Stiffness of machine tool spindle as a main factor for treatment accuracy, The scientific journal Facta Universitatis Vol.1, No 6, pp. 656-674.

3. Tri Prakosa and Rizky Ilhamsyah Agung Wibowo. (2013). Optimizing Static and Dynamic Stiffness of Machine Tools Spindle Shaft, for Improving Machining Product Quality, Journal of KONES Powertrain and Transport, vol. 20.

4. Holroyd, Pislaru, Crinela and Ford, Derek G Geoffrey. (2003). Determination of stiffness and damping sensitivity for computer numerically controlled machine tool drives, Proceedings of the Institution of Mechanical Engineers, Part C: Journal of Mechanical Engineering Science, no. ISSN 0954-4062, pp. 1165-1177.

5. Rastegari. A and Mobin. M Archenti. A. (2017). Condition Based Maintenance of Machine Tools: Vibration Monitoring of Spindle Units, IEEE 63nd Annual Reliability and Maintainability Symposium, 2017.

6. I V Kragelsky M N Dobychin V S Kombalov. (1982). Friction and Wear calculation methods. Pergamon press.

7. I.V.Kragelsky at al. (1981). Friction wear lubrication, Pulisher.

8. ISO13041-1 2004, Test conditions for numerically controlled turning machines and turning centres in Part 1: Geometric tests for machines with a horizontal workholding spindle.

9. NSK. (2012). Machine tool spindle bearing selection \& mounting guide.

10. M.M. Khonsari, E.R. Booser. (2001). Bearing Design and Lubrication, John Wiley and Sons.

11. Alecop. (2010). Eclipse machine Catalog.

12. M. S. Rabbi, S. C. Banik \& M. T. Islam, " Development of a Prototype CNC Router ", International Journal of Mechanical Engineering (IJME), Vol. 2, Issue 2, pp. 63-68

13. Hwa Jen Yap, Yun Suen Pai, Siow-Wee Chang \& Kee Msiah Yap, "Development of an Augmented Reality-Based G-Code Generator in Virtual CNC Milling Simulation ", International Journal of Computer Science and Engineering (IJCSE), Vol. 5, Issue 2, pp. 63-72

14. Digvijay Kushwaha, Raiv Ranjan, Vijendra Kumar Kushawaha \& Mohammad Tariq, " Evaluation and Optimization of Cutting Parameters for Turning of En-8 Steel: A Taguchi Approach ", International Journal of Mechanical Engineering (IJME), Vol. 6, Issue 4, pp. 35-44

15. K. Srinivasulu Reddy \& Solomon Dufera, "Additive Manufacturing Technologies ", BEST: International Journal of Management, Information Technology and Engineering (BEST: IJMITE), Vol. 4, Issue 7, pp. 89-112 


\section{AUTHOR'S PROFILE}

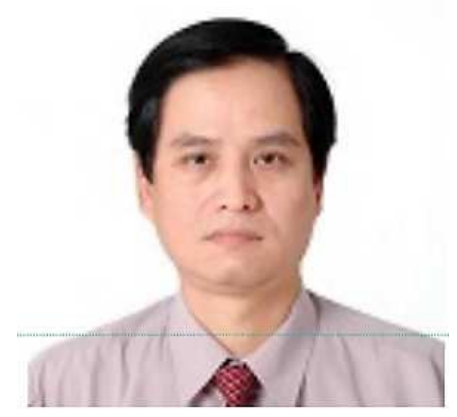

Hung Pham Van, Associate Professor in the Department of Machine tools and Tribology, School of Mechanical Engineering, Ha Noi University of Science and Technology, Vietnam, No 1 Dai Co Viet Stress, Hai Ba Trung District, Ha Noi City, 100000, Viet Nam. He got PhD degree from Ha Noi university Science and technology, Vietnam in 1998. His favourite research includes tribology in machine tool; Machine design and mechatronic systems.

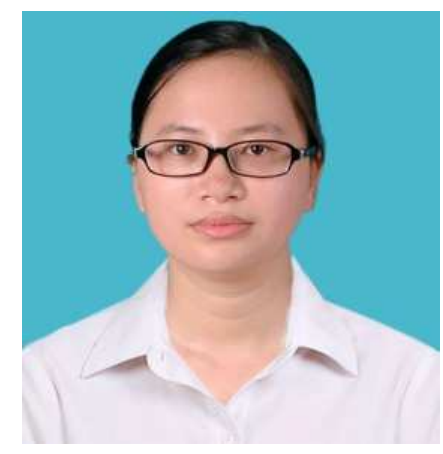

Duong Nguyen Thuy is currently a lecturer at Department of Machine tools and tribology, School of Mechanical Engineering, Ha Noi University of Science and Technology, Vietnam, No 1 Dai Co Viet Stress, Hai Ba Trung District, Ha Noi City, 100000, Viet Nam. She received her PhD degree from Ha Noi university Science and technology, Vietnam, in 2016. She research interests include tribology in machine tool and Machine design.

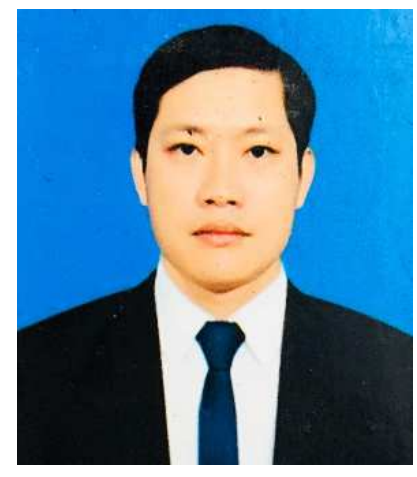

Tam Pham Minh is currently a lecturer at Faculty of Vehicle and Energy Engineering, Vinh University of Technology Education, 117, Nguyen Viet Xuan Street, Vinh City, Nghe An Province, Viet Nam. He received his Master degree from Ha Noi university Science and technology, Vietnam, in 2010. He research interests include Friction, Wear and Lubrication; Machine design. 